\title{
Ribosome Biogenesis in Archaea
}

\author{
Paola Londei $^{1 *}$ and Sébastien Ferreira-Cerca ${ }^{2 *}$ \\ ${ }^{1}$ Department of Molecular Medicine, University of Rome Sapienza, Rome, Italy, ${ }^{2}$ Biochemistry III - Regensburg Center \\ for Biochemistry, Institute for Biochemistry, Genetics and Microbiology, University of Regensburg, Regensburg, Germany
}

\section{OPEN ACCESS}

Edited by:

Eveline Peeters,

Vrije University Brussel, Belgium

Reviewed by:

Ute Kothe,

University of Lethbridge, Canada

Fabian Blombach,

University College London, United Kingdom

Henrik Nielsen,

University of Copenhagen, Denmark

*Correspondence:

Sébastien Ferreira-Cerca sebastien.ferreira-cerca@ur.de orcid.org/0000-0002-0522-843X

Paola Londel

paola.Iondei@uniroma1.it

Specialty section:

This article was submitted to

Biology of Archaea,

a section of the journal

Frontiers in Microbiology

Received: 28 March 2021

Accepted: 14 May 2021

Published: 22 July 2021

Citation:

Londei $P$ and Ferreira-Cerca $S$

(2021) Ribosome Biogenesis

in Archaea.

Front. Microbiol. 12:686977. doi: 10.3389/fmicb.2021.686977
Making ribosomes is a major cellular process essential for the maintenance of functional ribosome homeostasis and to ensure appropriate gene expression. Strikingly, although ribosomes are universally conserved ribonucleoprotein complexes decoding the genetic information contained in messenger RNAs into proteins, their biogenesis shows an intriguing degree of variability across the tree of life. In this review, we summarize our knowledge on the least understood ribosome biogenesis pathway: the archaeal one. Furthermore, we highlight some evolutionary conserved and divergent molecular features of making ribosomes across the tree of life.

Keywords: archaea, ribosome, ribosome biogenesis, ribosomal RNA, ribosomal proteins, RNA modifications

\section{RIBOSOMAL SUBUNIT COMPOSITION: ARCHAEAL SPECIFICITY AND COMMON FEATURES}

The ribosome is a universally conserved ribonucleoprotein (RNP) complex required for the synthesis of polypeptides from the intermediate molecule carrying the genetic information, the messenger RNA (Melnikov et al., 2012; Bowman et al., 2020). The birth of a ribosome itself is a highly energy-consuming and complicated orchestrated molecular dance that culminates in the formation of translation-competent mature ribosomal subunits (Nomura, 1999; Warner, 1999). The mature ribosome is composed of two ribosomal subunits, the small and large ribosomal subunits (hereafter SSU and LSU, respectively). These ribosomal subunits can be further divided into two main classes of structural components, the ribosomal RNA (rRNA) and the ribosomal proteins (r-protein). Despite its universality, the sequence and composition of the ribosomal subunits' structural components diverge across and within the different domains of life (Melnikov et al., 2012; Ban et al., 2014; Bowman et al., 2020). Notably, the sequence variabilities seen among the universally conserved ribosome structural components were recognized and harnessed at the end of the 1970s by the pioneering studies of Carl Woese and his collaborators and are still the cornerstone of modern molecular phylogenetic analysis and microbial taxonomy (Fox et al., 1977; Woese and Fox, 1977; Woese et al., 1990; Albers et al., 2013; Bahram et al., 2019).

Similar to their bacterial counterparts, archaeal ribosomes are composed of three types of rRNAs: the SSU $16 \mathrm{~S}$ rRNA and the LSU 23S and 5S rRNAs, which interact with 60-70 r-proteins, establishing an intricate macromolecular network (Melnikov et al., 2012; Ban et al., 2014; Bowman et al., 2020; Figure 1).

Up to now and due to the size and sequence similarities among organisms lacking a cell nucleus, the archaeal rRNA molecules have been largely seen as being of a prokaryotic nature (Figure 1). Particularly and in contrast to canonical prokaryotic rRNAs, most eukaryotic rRNAs 
A

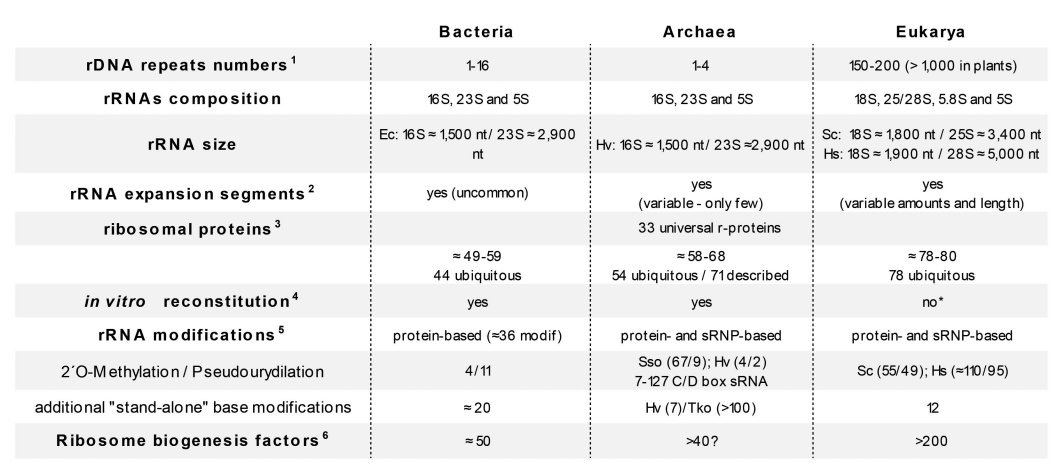

B

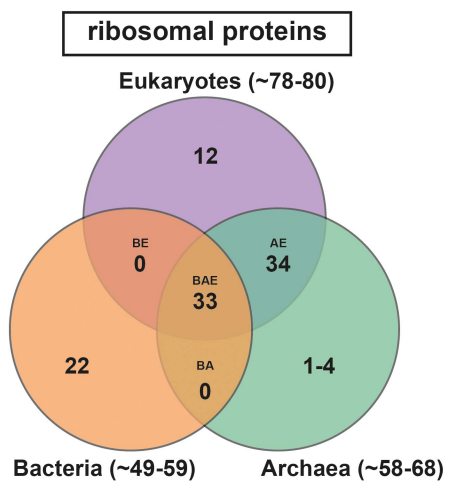

C

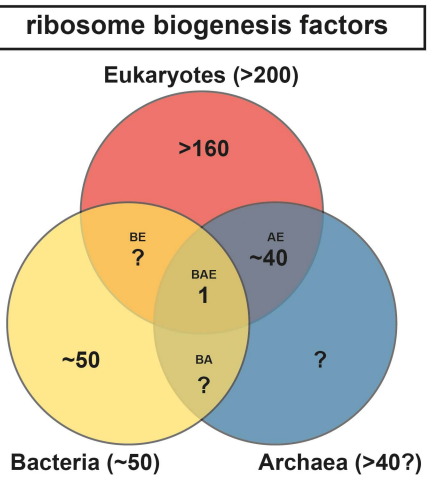

D

Order

\begin{tabular}{|c|c|c|c|c|c|c|c|c|}
\hline $\begin{array}{r}\text { Desulfurococcales } \\
\text { Thermoproteales } \\
\text { Sulfolobales }\end{array}$ & es1 & eS25 & eS26 & eS30 & eL13 & eL14 & $\begin{array}{c}\text { eL33 } \\
\vdots \\
\vdots \\
\vdots \\
\because\end{array}$ & eL34 \\
\hline Thermococcales & &,- &,$\cdots$ & & $\therefore$ & & & \\
\hline Methanopyrales & & $\therefore$ & $\therefore$ & $\because \because$ & $\because$ & & & \\
\hline Methanococcales & & 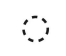 & $\vdots$ & $\because$ & $\because$ & & $\because$ & \\
\hline Methanobacteriales & & $\vdots$ & $\because$ & $\because$ & $\because$ & 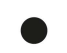 & $\vdots$ & \\
\hline Archaeoglobales & & 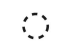 & $\because$ & 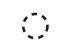 & $\because$ & $\because$ & $\vdots$ & $\because$ \\
\hline Thermoplasmatales & $\because \vdots$ & $\because$ & $\because$ & $\because$ & $\because$ & $\because$ & $\because$ & $\because$ \\
\hline Halobacteriales & $\because$ & $\because \vdots$ & $\because$ & $\vdots$ & $\vdots$ & $\because$ & $\because$ & $\because \because$ \\
\hline
\end{tabular}

FIGURE 1 | Ribosome and ribosome biogenesis key features overview across the tree of life. (A) Summary of ribosome and ribosome biogenesis key features. Modified from Ferreira-Cerca (2017) according to ${ }^{1}$ (Hadjiolov, 1985; Warner, 1999; Klappenbach et al., 2001; Stoddard et al., 2015); ${ }^{2}$ (Gerbi, 1986, 1996; Armache et al., 2013; Parker et al., 2015; Petrov et al., 2015); ${ }^{3}$ (Lecompte et al., 2002; Nakao et al., 2004; Yutin et al., 2012); ${ }^{4}$ (Londei et al., 1986; Sanchez et al., 1990,

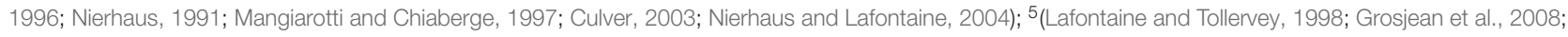
Dennis et al., 2015; Sharma and Lafontaine, 2015; Krogh et al., 2016; Sloan et al., 2016; Taoka et al., 2018; Coureux et al., 2020; Grünberger et al., 2020; Sas-Chen et al., 2020); and ${ }^{6}$ (Hage and Tollervey, 2004; Thomson et al., 2013; Woolford and Baserga, 2013; Ebersberger et al., 2014; Grosjean et al., 2014; Henras et al., 2015). The detailed list of putative eukaryotic ribosome biogenesis factors conserved in archaea is depicted in Ebersberger et al. (2014). Abbreviations used: Sso, Saccharolobus solfataricus; Hv, Haloferax volcanii; Tko, Thermococcus kodakarensis; Hs, Homo sapiens; Sc, Saccharomyces cerevisiae. (B,C) Summary of shared ribosomal proteins (B) and ribosome biogenesis factors $\mathbf{( C )}$ across the three domains of life. Numbers of $\mathrm{r}$-proteins and putative ribosome biogenesis factors sequence homologs shared between bacteria, archaea, and eukarya (BAE); bacteria, archaea (BA), archaea and eukarya (AE), bacteria and eukarya (BE), or unique to bacteria (B), or archaea (A), or eukarya (E), are indicated [based on (Lecompte et al., 2002; Hage and Tollervey, 2004; Nakao et al., 2004; Márquez et al., 2011; Yutin et al., 2012; Thomson et al., 2013; Woolford and Baserga, 2013; Ban et al., 2014; Ebersberger et al., 2014; Grosjean et al., 2014; Henras et al., 2015; Coureux et al., 2020; Nürenberg-Goloub et al., 2020)]. (D) Exemplary gene distribution of selected archaeal ribosomal proteins shared between archaea and eukaryotes across two major archaeal Phyla. Black circle denotes the presence and open circle denotes the absence of sequence homolog for the indicated ribosomal protein of the small (S) or large (L) ribosomal subunits, respectively. Adapted from Lecompte et al. (2002); Yutin et al. (2012) using the nomenclature proposed in Ban et al. (2014). 
are characterized by the presence of so-called expansion segments (ES), which are additional RNA elements of various sizes incorporated into the universal prokaryotic rRNA core (Gerbi, 1996; Bowman et al., 2020; Figure 1). These ES increase the size and complexity of the respective rRNAs; however, recent analyses have provided evidence for the presence of such ES in both bacteria and archaea (Armache et al., 2013; Penev et al., 2020; Tirumalai et al., 2020; Stepanov and Fox, 2021). Although most of these sequence additions are limited in size and number (Armache et al., 2013; Penev et al., 2020; Tirumalai et al., 2020; Stepanov and Fox, 2021), larger ES, similar in size to those commonly observed in eukaryotes, have been recently described in the Asgard archaeal phylum (Penev et al., 2020), which is proposed to be the cradle of the eukaryotic lineage (Spang et al., 2015; Zaremba-Niedzwiedzka et al., 2017; Liu Y. et al., 2021). However, a common evolutionary relationshipbased on sequence and/or structure homology-of the larger archaeal and eukaryotic ES could not be established (Penev et al., 2020). Recently, a role of some of these ES in ribosomal biogenesis and/or function has been established in eukaryotes (Ramesh and Woolford, 2016; Fujii et al., 2018; Díaz-López et al., 2019; Shankar et al., 2020). Accordingly, determining both the respective function(s) and evolutionary origin(s) of these additional rRNA segments in archaea is of general interest for the field and will be crucial to distinguish between the archaeal origin of eukaryotic features from the independent but convergent evolution trajectories of structural elements present in both archaea and eukaryotes.

The archaeal ribosomal proteins can be divided into three different groups: (1) the universally conserved r-proteins that form, with the rRNAs, the universal ribosomal core (Melnikov et al., 2012), (2) the r-proteins exclusively shared between archaea and eukaryotes, and (3) the archaeal-specific r-proteins (Lecompte et al., 2002; Márquez et al., 2011; Yutin et al., 2012; Ban et al., 2014; Coureux et al., 2020; Nürenberg-Goloub et al., 2020; Figure 1). The absence of exclusively shared r-proteins between bacteria and archaea remains an intriguing observation.

Among the 70 different r-proteins described in archaea, only 54 are known to be ubiquitous across archaea; among them, 33 are universally conserved (Lecompte et al., 2002; Yutin et al., 2012; Ban et al., 2014; Figure 1). The composition variability of the r-protein complement also correlates with a general decrease in complexity of the r-proteins composition at the domain scale (Lecompte et al., 2002; Yutin et al., 2012; Figure 1). In other words, the r-protein counterpart of the last archaeal common ancestor was likely more complex than that of most of its descendent lineages (Lecompte et al., 2002; Yutin et al., 2012). The functional consequences and additional adaptations underlying such r-protein reductive evolution for archaeal ribosome biogenesis and function is currently unknown. Furthermore, recent studies also indicate the presence of archaeal-specific ribosomal proteins (Márquez et al., 2011; Coureux et al., 2020; Nürenberg-Goloub et al., 2020), suggesting that the discovery of new additional archaeal-specific r-proteins is still incomplete. Last, organism-specific insertion, extension, deletion, or sequence variations within conserved r-proteins are not unusual, and may play an important role for the cellular adaptation of ribosome biogenesis and function (Ferreira-Cerca et al., 2007; Melnikov et al., 2018; Dao Duc et al., 2019). However, the functional contributions of the additional archaealspecific r-protein features for ribosome assembly and function remain to be explored.

Another particularity of the r-protein composition of some archaeal ribosomal subunits is the presence of intra- and intersubunit promiscuous r-proteins, which leads to an increase of the respective r-protein stoichiometry and to the presence of shared structural components of both the SSU and LSU (Armache et al., 2013). This peculiarity is in stark contrast to what is typically observed in the bacterial and eukaryotic systems, in which r-proteins are thought to be exclusive structural components of one or the other ribosomal subunit present in one copy per ribosomal subunit, with the exception of the LSU stalk r-proteins (Armache et al., 2013). The functional implications of these molecular peculiarities remain to be analyzed.

In conclusion, the core structural components of the archaeal ribosomal subunits are of prokaryotic origin, to which archaealspecific and shared archaeal-eukaryotic features have been added. Together, the structural and functional constraints and/or advantages of these structural and compositional idiosyncrasies for ribosome biogenesis and function remain to be explored.

\section{rRNA ORGANIZATION, SYNTHESIS, AND PROCESSING IN ARCHAEA}

The organization of the rRNA genes and the maturation of the transcripts thereof to yield mature rRNA molecules is the most widely studied and best understood aspect of ribosome biogenesis in archaea (Yip et al., 2013; Ferreira-Cerca, 2017; Clouet-d'Orval et al., 2018). Because a large literature, including a number of excellent reviews, exist on this topic, here only the features most relevant from an evolutionary point of view are described.

As described, archaeal ribosomes are composed of one $30 \mathrm{~S}$ and one $50 \mathrm{~S}$ ribosomal subunit, the former containing a $16 \mathrm{~S}$ rRNA and the latter $23 \mathrm{~S}$ and $5 \mathrm{~S}$ rRNAs. The genomic organization of the rRNA genes, however, presents marked differences in the different archaeal groups. Most euryarchaeota have a typically bacterial operon organization with the 16S23S-5S rRNA genes linked in this order, separated by spacer sequences, and transcribed all together. In most cases the spacer separating the $16 \mathrm{~S}$ and the $23 \mathrm{~S}$ rRNA genes contains an Ala-tRNA gene; some euryarchaea also have a second tRNA gene, CystRNA, in the $3^{\prime}$ ETS downstream of the 5S rRNA gene (Figure 2). By contrast, in the crenarchaeota and probably in most members of the TACK superphylum, the 5S rRNA genes are physically separated from the other two larger rRNAs and transcribed independently (Figure 2). There are also a few special situations, such as that of the euryarchaeon Themoplasma acidophilum, where the three 16S, 23S, and 5S rRNA genes are unlinked and separately transcribed (Yip et al., 2013; Brewer et al., 2020; Figure 2).

The primary rRNA transcripts are maturated following pathways that follow neither the bacterial nor the eukaryal paradigm, albeit having features reminiscent of both. 


\section{A}

\section{rRNA operon organization bhb motif}

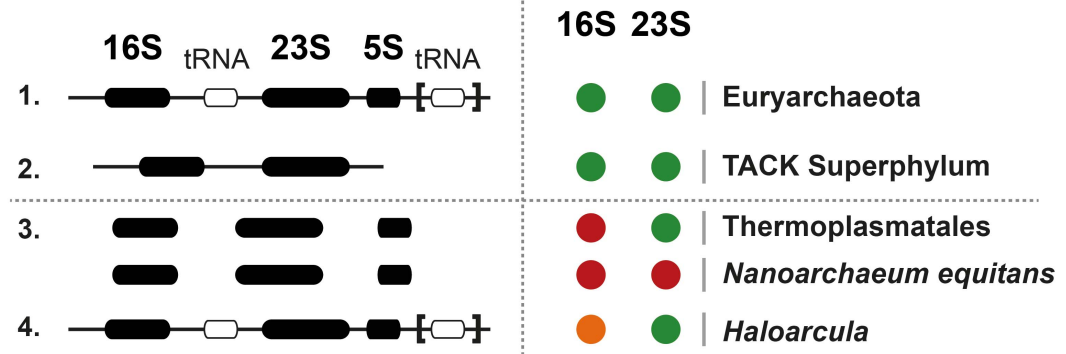

B
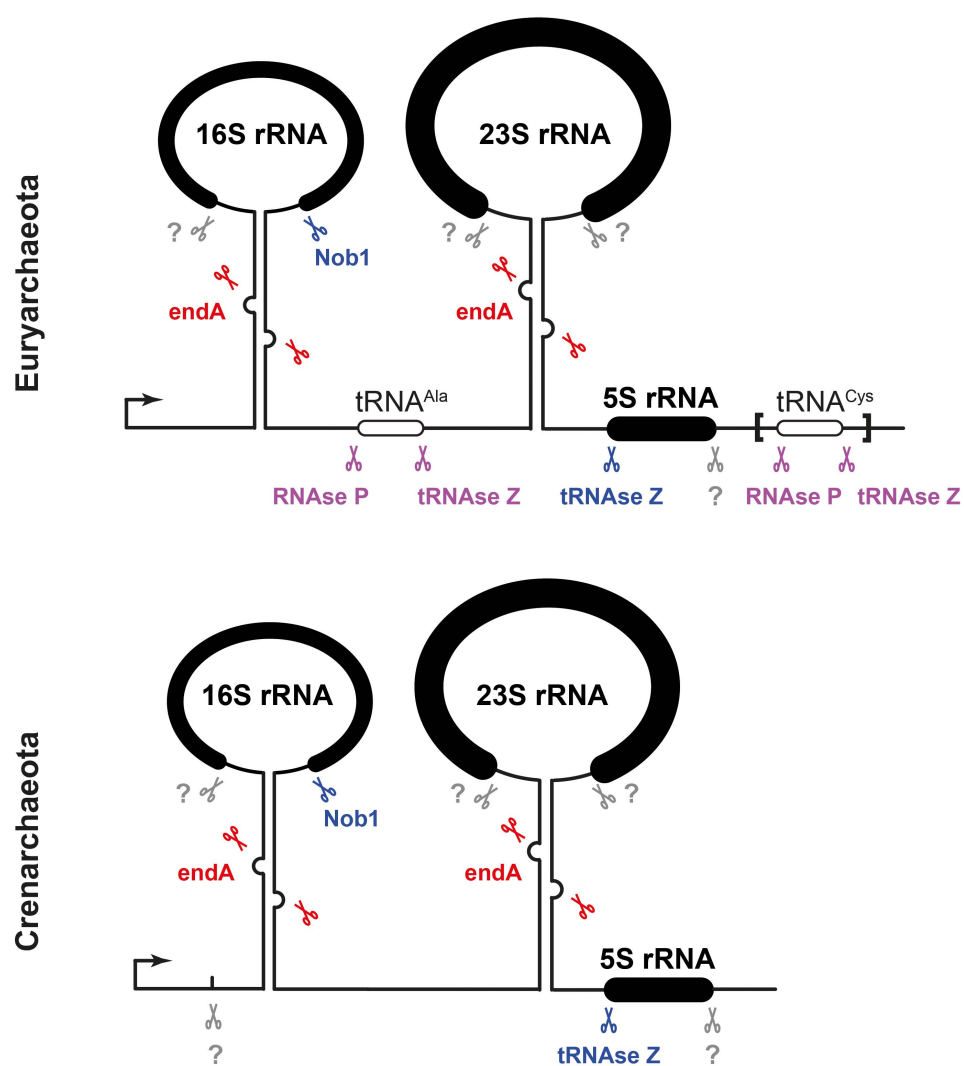

FIGURE 2 | rDNA gene organization and processing of pre-rRNA in archaea. (A) Ribosomal DNA gene organization and rRNA BHB motif conservation across archaea. A selected survey of archaeal rRNA operon organizations suggests two predominant classes of linked rRNA organization found in representative organisms of the Euryarchaeota and TACK Superphylum (Thaumarchaeota-Aigarchaeota-Crenarcheota-Korarchaeota) and one minor class of unlinked organization (e.g., Thermoplasmata class/Nanoarchaeum equitans). 16S and 23S rRNAs processing stem secondary structures were predicted using the ViennaRNA Web servers. Presence of predicted BHB is indicated in black. Presence of heterogeneous rRNA operons with heterogeneous presence of BHB motif within the processing stem is depicted in orange (Haloarcula genus). Absence of predictable BHB motifs is depicted by a red circle (e.g., Thermoplasmata class/Nanoarchaeum equitans). Modified from Jüttner et al. (2020) under CC-BY License. (B) Schematic representation of exemplary rRNA processing sites and the known respective ribonuclease activities required for the maturation or the pre-rRNA are indicated. Unknown activities are indicated in gray, putative activities in lilac, activities base on in vitro analysis in blue, and activities based on in vivo analysis in red. Upper panel represents common organization found in Euryarchaeota and lower panel in Crenarchaeota. Modified from Ferreira-Cerca (2017); Jüttner et al. (2020).

As in bacteria, the sequences flanking the rRNA genes have extended complementarity and pair, forming double-helical stems that are the target of certain endonucleases starting rRNA maturation. However, although, in bacteria, these stems are cleaved by RNAse III, in most archaea, they typically contain
Bulge-helix-Bulge (BHB) motifs that are recognized and cleaved by the archaeal-specific endA splicing endonuclease (Tang et al., 2002; Ferreira-Cerca, 2017; Clouet-d'Orval et al., 2018; Qi et al., 2020; Schwarz et al., 2020; Figure 2). Consequently, the pre-16S and pre-23S rRNAs are ligated and first released 
in a circular pre-rRNA form, which is subsequently opened and matured by other enzymes that have not yet been characterized (Tang et al., 2002; Ferreira-Cerca, 2017; Clouetd'Orval et al., 2018; Jüttner et al., 2020; Qi et al., 2020; Schwarz et al., 2020). For a comprehensive review of the rRNA maturating/modifying enzymes, see Clouet-d'Orval et al. (2018) and Ferreira-Cerca (2017).

In certain members of the crenarchaeota, the processing of $16 \mathrm{~S}$ rRNA has features that present some homology with the eukaryotic process; specifically, there are endonucleases that introduce 1-2 cuts within the 5'ETS (Durovic and Dennis, 1994; Figure 2). The most distal of these processing sites, termed site 0 , lies some 70 nucleotides ahead of the $16 \mathrm{~S}$ mature $5^{\prime}$ end, is probably conserved in most crenarchaeota, and has similarity to the processing site termed A0 in eukaryotes. Site A0 is generally present in eukaryotic pre-rRNAs and is one of the earliest processing sites starting its maturation (Mullineux and Lafontaine, 2012). In archaea, endonucleolytic cleavage at site 0 is independent of the formation of the processing stems containing the $\mathrm{BHB}$ motifs. Instead, its recognition is guided by a specific sequence containing a conserved CUU motif also found in the eukaryotic counterpart. This CUU motif is shown to be essential for cleavage in S. solfataricus (Ciammaruconi and Londei, 2001). Notably, in the eukarya, cleavage at site A0 requires a RNP particle containing the small nucleolar RNA $\mathrm{U} 3$, but in the archaea this does not seem to be the case. The archaeal endonuclease cutting at site 0 has not yet been identified; interestingly, it seems to be closely associated with the $60 \mathrm{kDa}$ chaperonin, at least in S. solfataricus (Ruggero et al., 1998).

Although homologs of eukaryotic small nucleolar RNAs do not seem to be involved in rRNA processing in archaea, they do participate massively in another prominent feature of archaeal rRNA maturation, that is, guiding chemical modifications of specific nucleotides, which is described in the next paragraph.

\section{RIBOSOMAL RNA MODIFICATIONS}

RNA modifications were discovered in the early 1950s, and since then, more than 100 different types of chemical modifications have been described (Littlefield and Dunn, 1958; Boccaletto et al., 2018). These modifications are expanding the chemical and structural properties of the classical RNA alphabet (Li and Mason, 2014; Kadumuri and Janga, 2018).

Ribosomal RNA modifications are found in all rRNAs studied thus far (Piekna-Przybylska et al., 2008; Boccaletto et al., 2018); however, their diversity (respective chemical nature, number, and position) can be diverging across archaea (Grosjean et al., 2008; Dennis et al., 2015; Boccaletto et al., 2018; Coureux et al., 2020; Sas-Chen et al., 2020). rRNA modifications can be grouped into two main types: (1) base and (2) ribose modifications. Furthermore, the machineries involved in the rRNA modification process can be also subdivided into two major groups: (1) stand-alone enzymes, which are found across all domains of life, and (2) RNA-guided modifications, which utilize RNP complexes to guide and modify the target rRNA in an RNA sequence-dependent manner (Lafontaine and Tollervey, 1998;
Omer et al., 2003; Yip et al., 2013). Notably, these RNP complexes are ubiquitous in both archaea and eukaryotes but are absent from bacteria and are responsible for the two major types of rRNA modifications, i.e., 2'O-methylation of the ribose moiety by the C/D box sRNPs and isomerization of the uridine base into pseudouridine by the H/ACA box sRNPs (Lafontaine and Tollervey, 1998; Omer et al., 2003; Yip et al., 2013). Moreover, in eukaryotes, few snoRNPs do not have any known rRNA modification function but are instead required for prerRNA processing (Lafontaine and Tollervey, 1998; Sharma and Lafontaine, 2015; Sloan et al., 2016). Among these, the snoRNA $\mathrm{U} 3$ is required for early processing steps of the SSU and to avoid premature folding of the SSU central pseudoknot structure (Baßler and Hurt, 2019; Klinge and Woolford, 2019). In archaea, U3 and snoRNPs facilitating rRNA processing and folding independently of rRNA modification activity are not known. More details about these two classes of RNPs and their rRNA modifications in archaea can be found in the two accompanying reviews in this special issue by Randau and collaborators (C/D box sRNPs; Breuer et al., 2021) and Kothe and collaborators (H/ACA box sRNPs; Czekay and Kothe, 2021).

In addition to the two main types of rRNA modifications mentioned, additional base modifications are also found. Commonly, base methylations $(\mathrm{m} 1, \mathrm{~m} 3, \mathrm{~m} 5, \mathrm{~m} 6 \mathrm{~A}, \ldots)$ and also acetylation or larger types of modifications (e.g., acp3) are decorating the rRNAs (Piekna-Przybylska et al., 2008; Boccaletto et al., 2018). Generally, most of these modifications cluster within the ribosomal subunit functional centers (A-, $\mathrm{P}$-, E-sites, and subunit bridges) and are believed to stabilize and/or support the activity of the translation machinery (PieknaPrzybylska et al., 2008; Sharma and Lafontaine, 2015; Sloan et al., 2016). Interestingly, the position and/or chemical nature of these modifications is apparently flexible across the tree of life, suggesting that the functional contribution of the respective rRNA modification(s) in their respective structural environments prevails over their exact chemical nature and/or relative position (Piekna-Przybylska et al., 2008; Sharma and Lafontaine, 2015; Sloan et al., 2016; Ferreira-Cerca, 2017).

The total amounts and types of rRNA modifications strongly vary across archaea. For instance, halophilic archaea possess a lower total amount of rRNA modifications (e.g., H. volcanii $\sim 10$ known modifications; Grosjean et al., 2008). For example, the archaeal homologs of the eukaryotic methyltransferase Nep1 are not found in the phylogenetically related Methanogen class II and Haloarchaea (see also Figure 3). This decrease in the number of RNA modifications also correlates with a generally reduced amount of r-proteins and ribosome biogenesis factors in these organisms (Lecompte et al., 2002; Yutin et al., 2012; Ebersberger et al., 2014; see above and below). In contrast, the total amount of rRNA modifications in thermophiles and hyperthermophiles is particularly increased (Dennis et al., 2015). For example, representative organisms of the Thermococcales order, which can grow at remarkably high temperatures (near the boiling point of water), contain a large amount of base acetylations, presumably introduced by the archaeal homolog of the eukaryotic RNA cytidine acetyltransferase Kre33/Nat10 (Sleiman and Dragon, 2019; Coureux et al., 2020; 


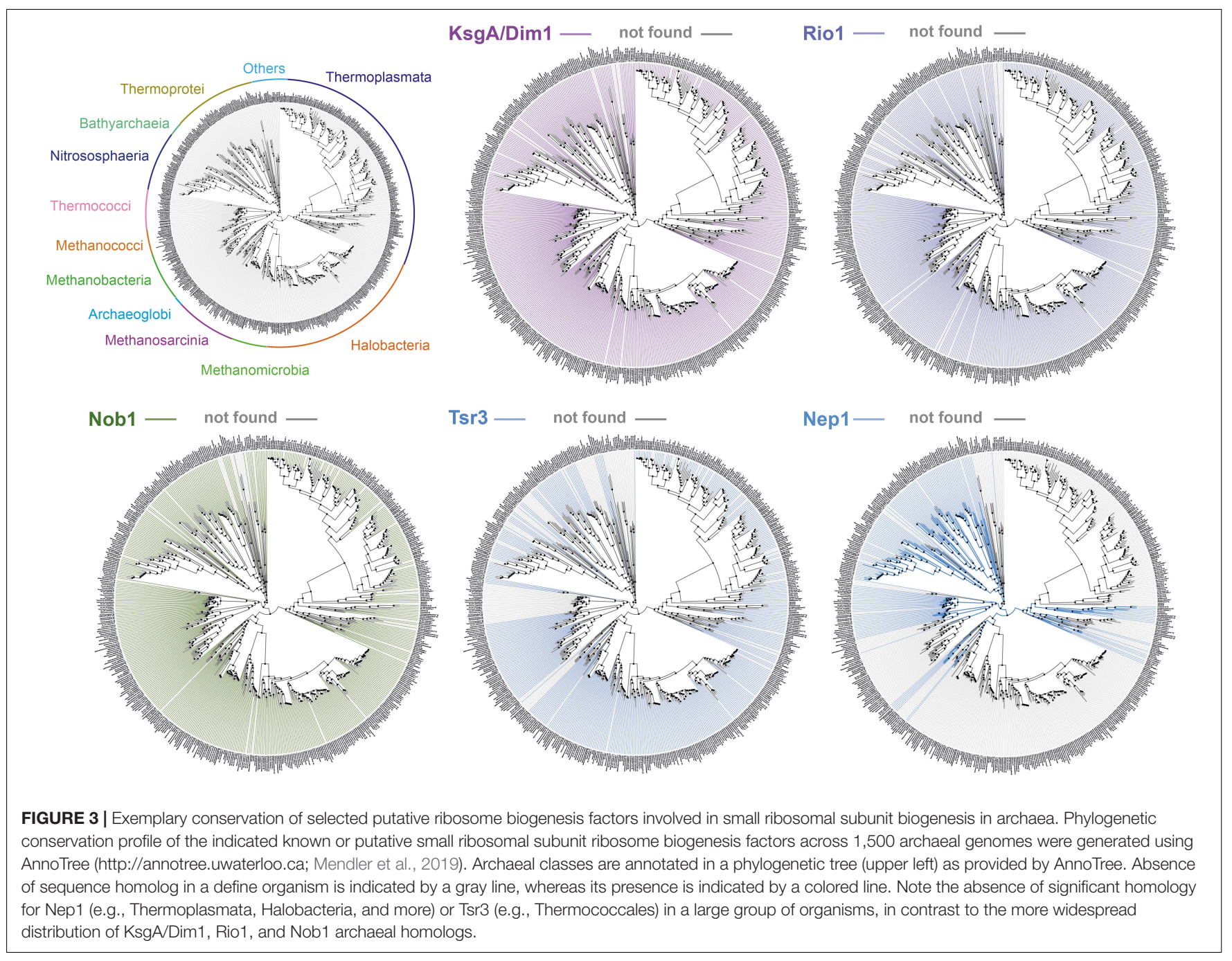

Grünberger et al., 2020; Sas-Chen et al., 2020). Moreover, and in contrast to the clustered distribution of rRNA modifications normally observed, these acetylations are scattered throughout the rRNA sequences (Coureux et al., 2020; Grünberger et al., 2020; Sas-Chen et al., 2020). Furthermore, the total amount of these acetylations seems to vary according to the growth temperature (Sas-Chen et al., 2020).

Remarkably, among all the known stand-alone enzymes, the SSU dimethyltransferase KsgA/Dim1 carrying the dimethylation of two universally conserved adenosines at the $3^{\prime}$ end of the SSU rRNA is the only almost universally conserved factor involved in ribosome biogenesis (Lafontaine et al., 1994; Connolly et al., 2008; Seistrup et al., 2017; Knüppel et al., 2021). Despite its widespread distribution, several functional aspects of the KsgA/Dim1 biology, such as assembly/release mechanisms and the modification process itself (e.g., completion) strikingly diverge between different organisms and across the different domain of life (Van Buul et al., 1984; Formenoy et al., 1994; Lafontaine et al., 1994; Connolly et al., 2008; Zorbas et al., 2015; Ghalei et al., 2017; Seistrup et al., 2017; Knüppel et al., 2021; Liu K. et al., 2021).
Overall, these observations suggest that the relative amount of rRNA modifications and their diversity may reflect organismspecific adaptation to their respective environmental conditions and/or organism-specific evolutionary trajectories (Dennis et al., 2015; Seistrup et al., 2017; Sas-Chen et al., 2020; Knüppel et al., 2021). The functional significance of the variability in rRNA modifications, of the presence of different modification machineries on the ribosome biogenesis pathway in archaea, and how these machineries have contributed to (re-)shape the ribosome assembly pathway remains to be determined.

\section{ASSEMBLY OF ARCHAEAL RIBOSOMES: IN VITRO STUDIES}

The capability of bacterial ribosomes to assemble spontaneously in vitro from the separate RNA and protein components was first demonstrated in the late 60's by the Nomura laboratory with Escherichia coli 30S subunit (Traub and Nomura, 1968) and later by the Nierhaus laboratory with the $50 \mathrm{~S}$ subunit from the same organism (Nierhaus and Dohme, 1974). Ribosomes from 
other bacterial species were also successfully reconstituted in vitro (Green and Noller, 1999; Agalarov et al., 2016).

These experiments are important in showing that, even in a huge macromolecular complex such as the ribosome, the components contain in themselves all the necessary information to interact in an orderly way so as to form a functional particle. Even more importantly, they highlight a definite assembly hierarchy, in which a subset of ribosomal proteins starts the ribosome biogenesis process by binding directly to specific sites on the rRNA. These "early assembly" proteins, together with the rRNA, create a "core particle" that has to undergo certain conformational changes before binding the missing proteins and being converted into the final functional particle.

Experiments of in vitro assembly with purified components, could define an "assembly map," i.e., the stepwise binding of ribosomal proteins to the rRNAs leading to the formation of intermediate particles that are finally converted into a complete functional ribosomal subunit (Roth and Nierhaus, 1980). However, the necessary experimental conditions (e.g., time, temperature, and ionic strength, etc.) to enable these in vitro reconstitution experiments are commonly incompatible with the physiological conditions of the respective organisms, thereby suggesting the presence of facilitating molecular mechanisms in vivo.

Among these mechanisms, the "assembly gradient" originally proposed by Knud Nierhaus suggests that cotranscriptional and directional assembly of r-proteins ( $5^{\prime}$ to $3^{\prime}$ direction), facilitate the initial steps of ribosomal assembly in vivo (Nierhaus, 1991). Similar principles of ribosomal assembly seem to apply in some eukaryotes [see, e.g., Cheng et al. (2017); de la Cruz et al. (2015); Ferreira-Cerca et al. (2007), but see also Cheng et al. (2019) and references therein] and may, therefore, likely operate in the archaeal context. For example, our recent work suggests a $5^{\prime}$ to $3^{\prime}$ coordination of the initial pre-rRNA maturation steps in H. volcanii (Jüttner et al., 2020). Moreover, recent studies in Sulfolobales suggest local clustering of the rRNA and r-protein operon genes, which may potentially have implication for early steps of ribosome assembly in some archaea (Takemata and Bell, 2021). However, the conservation of the topology and organization of the ribosome synthesis machinery remains to be explored (Cockram et al., 2021; Sobolev et al., 2021).

Furthermore, additional ribosome biogenesis factors facilitating or speeding up ribosome assembly were also identified later (Bunner et al., 2010; Nikolay et al., 2018; see below). Even if the pathways for in vitro ribosome assembly are likely to be at least in part different from those adopted in vivo, the results from in vitro studies reveal that ribosome biogenesis is a highly coordinated process that requires a number of specific sequential steps to be completed successfully.

In vitro reconstitution experiments were also employed to explore the degree of conservation of ribosomal components among different bacterial species. It was demonstrated that hybrid, active ribosomes could be successfully reconstituted from proteins and rRNA from different sources, thus further highlighting the high degree of functional and structural conservation of bacterial ribosomes (Higo et al., 1973; Vogel et al., 1984).
That archaeal ribosomes were also capable of spontaneous self-assembly in vitro was demonstrated some years later with the particles of two different extremophilic archaea: the 50S subunits of Saccharolobus (formerly Sulfolobus) solfataricus (Londei et al., 1986), an extreme thermophile, and both 30 S and 50 S subunits of Haloferax mediterranei, a halophilic organism (Sanchez et al., 1990, 1996). The challenge here was not only to obtain spontaneous reassembly of the ribosomal particles from a different domain of life, but also to explore how living in extreme environments affected ribosome biogenesis.

The thermophilic archaeon $S$. solfataricus is a particularly interesting case because it thrives optimally at a temperature of $80-85^{\circ} \mathrm{C}$ and because it is known to have more proteinrich ribosomes than its bacterial counterparts (Schmid and Böck, 1982; Londei et al., 1983). S. solfataricus 50S subunits could be functionally reassembled from the separate RNA and protein components only at high temperatures $\left(80^{\circ} \mathrm{C}\right)$ and using high polyamine (thermine) concentrations. Interestingly, the best conditions for Sulfolobus 50S subunits in vitro assembly entailed a two-step procedure such as for the case of the corresponding E. coli particles. As in E. coli, the first step is performed at a relatively low temperature $\left(60^{\circ} \mathrm{C}\right)$ and yields complete but functionally inactive particles. Activation is only achieved upon incubation at temperatures close to the one optimal for Sulfolobus growth $\left(85^{\circ} \mathrm{C}\right)$, suggesting the requirement for a temperature-driven conformational change. The presence of a high concentration of the polyamine thermine, which is physiologically present in S. solfataricus, is most probably required to stabilize and promote the RNA/protein interactions (Londei et al., 1986).

Notably, however, it was never possible to achieve in vitro reconstitution of functional $S$. solfataricus 30 S subunits despite the lower complexity of these particles with respect to the $50 \mathrm{~S}$ ones. More precisely, in vitro assembly of $30 \mathrm{~S}$ particles containing the 16S rRNA and the whole complement of $30 \mathrm{~S}$ ribosomal proteins was easily obtained, but they were not active in translation (Londei, unpublished). The reason for this unexpected result is unclear. It may be due to the substantially higher protein content of $S$. solfataricus 30 S subunits with respect to bacterial particles (28 r-proteins vs $20-21$ ), and/or to the requirement for some additional assembly-promoting factor (see below). If so, biogenesis of $S$. solfataricus 30 S subunits may present interesting homologies with the eukaryotic process that would be worth exploring in better detail.

As to halophilic ribosomes, Haloferax mediterranei 30 S and $50 \mathrm{~S}$ subunits could be reassembled successfully only at very high concentrations of salt, close to the physiological concentration within the cell. Two types of monovalent cations were the most effective in promoting reconstitution, $\mathrm{K}^{+}$and $\mathrm{NH}_{4}{ }^{+}$. Unlike what happens for both $E$. coli and S. solfataricus, $H$. mediterranei ribosomes could be reconstituted using a single-step incubation at $42^{\circ} \mathrm{C}$., i.e., within the optimal temperature range for physiological growth of this organism. The procedure was similar for $30 \mathrm{~S}$ and $50 \mathrm{~S}$ subunits except that reconstitution of $30 \mathrm{~S}$ subunits had a higher tolerance to ionic strength than that of $50 \mathrm{~S}$ subunits and was independent of the $\mathrm{Mg}^{2+}$ concentration present in the assay (Sanchez et al., 1990, 1996). 
One important outcome of the in vitro reconstitution experiments with archaeal ribosomes was the possibility of studying the assembly pathways and to identify the assemblyinitiating r-proteins. Indeed, using purified rRNA and r-proteins from $S$. solfataricus large ribosomal subunits, it was shown that the initial RNA-protein interactions leading to the formation of a definite but still incomplete assembly intermediate did not require high temperatures, but took place optimally at about $20^{\circ} \mathrm{C}$ (Altamura et al., 1991). High temperatures, plus the missing proteins, were instead mandatory to convert the low-temperature assembly intermediate into active complete subunits. The assembly intermediate contains 16 of the 34 total $50 \mathrm{~S}$ subunit r-proteins; among these, the actual primary RNAbinding proteins were identified by experiments of rRNA binding to membrane-immobilized $S$. solfataricus large subunit proteins. These turned out to be 8-9 r-proteins, well in accordance with the number of primary RNA-binding proteins in bacterial $50 \mathrm{~S}$ ribosomes. It is probable that some, or even all, of these proteins belong to the universally conserved set of r-proteins, but because their identity was not assessed in the study in question, this cannot be stated with certainty. In any event, that the r-proteins present in the low-temperature-assembly intermediate are the innermost in the body of the $50 \mathrm{~S}$ subunit was also confirmed by preparing ribosomal "cores," i.e., stripping the outer r-proteins with high concentrations of $\mathrm{LiCl}$, a salt known to disrupt weak RNA/protein interactions (Altamura et al., 1991).

Finally, the availability of methods for in vitro reconstitution of archaeal ribosomes allows exploring the degree of evolutionary conservation of the assembly pathways and of rRNA/r-protein interactions. In one study, it was found that incubation of S. solfataricus LSU proteins with the $23 \mathrm{~S}$ rRNAs from a distantly related archaeon ( $H$. mediterranei) or from $E$. coli led to the formation of a definite and compact $40 \mathrm{~S}$ particle, containing most of the proteins previously identified as early assembly proteins in S. solfataricus, including all of the primary RNA-binding ones (Altamura et al., 1991). These results suggest that the basic architecture of the ribosome and the primary rRNA/r-protein interactions are conserved to a large extent in the two prokaryotic domains of life.

Other data in agreement with this surmise is the complete functional exchangeability of $5 \mathrm{~S}$ rRNA between $S$. solfataricus and E. coli LSUs (Teixidò et al., 1989).

In contrast, incubation of the $S$. solfataricus whole complement of 50S ribosomal proteins with LSU rRNAs from yeast produced no particle, but only an heterogeneous array of RNP complexes, further indicating that both ribosome structure and assembly pathways have undergone a marked divergence from the prokaryotic model in the course of eukaryotic evolution (Altamura et al., 1991).

In summary, probably the most important lesson to be learned from the in vitro assembly experiment is that strong similarities exist in the basic architecture and assembly pathways of archaeal and bacterial ribosomes in spite of the presence of unique features in both and of certain "eukaryotic" features in archaea, especially as regards rRNA structure and maturation. The greater complexity of ribosome assembly in eukaryotes is best documented by the fact that, despite many efforts, in vitro reconstitution of functional eukaryotic ribosomes from the separated components was largely unsuccessful. The one study claiming success in this task was performed with the ribosomes of Dictyostelium discoideum (Mangiarotti and Chiaberge, 1997). Interestingly, in vitro assembly of functional D. discoideum ribosomes could not be achieved using $18 \mathrm{~S}$ and $28 \mathrm{~S}$ rRNA species from mature cytoplasmic ribosomes but required still immature rRNA extracted from nuclear ribosomes. Furthermore, a small RNA species-presumably nucleolar-is apparently required for successful reconstitution. Although this study was never replicated, it agrees with the fact that ribosome assembly is inherently more complex in eukaryotes, developing along a pathway that makes use of many additional extra-ribosomal nuclear/nucleolar factors. Also, the similarity in operon organization and in processing pathways of archaeal and bacterial rRNAs with respect to the eukaryotic ones speaks in favor of a greater evolutionary conservation between the two prokaryotic domains. The presence of a single cellular compartment in which everything happens, from transcription of rRNAs, to maturation of rRNA transcripts, to ribosome assembly and activation, must have dictated the need for a simpler and more streamlined process of ribosome biogenesis than it is the case for eukaryotes. However, more work is required to assess these points, especially in vivo experiments, which, at present, are almost completely lacking in archaea.

\section{RIBOSOME BIOGENESIS FACTORS: ARCHAEAL SPECIFICITY AND SHARED FEATURES}

Ribosome biogenesis also requires the participation of additional ribosome biogenesis factors, also known as assembly factors or trans-acting factors. These factors have been analyzed in great detail in bacteria and eukaryotes. Generally, these factors transiently interact with the nascent ribosomal subunits and are believed to facilitate the ribosome biogenesis process. Among these factors, a significant fraction homes various enzymatic activity, mostly NTPase activity (ATPase, GTPase, and RNA helicases...), which may contribute to promote energy-dependent steps of the ribosomal subunit biogenesis process. Interestingly, whereas GTP-dependent processes are predominant in bacteria, ATP-dependent processes are strikingly more frequent in Eukaryotes (Shajani et al., 2011; Thomson et al., 2013; Davis and Williamson, 2017; Baßler and Hurt, 2019; Klinge and Woolford, 2019). Paradoxically, and despite the universal conservation of the ribosomal subunits, most of the ribosome biogenesis factors are (1) not conserved across evolution, and (2) their numbers are dramatically increasing in eukaryotes (Hage and Tollervey, 2004; Ebersberger et al., 2014; Ferreira-Cerca, 2017; Figures 1, 3). This observation suggests that the ribosome biogenesis pathway has been reengineered multiple times during evolution and may reflect early adaptation to molecular constraints present within the respective cellular lineage ancestors. Still, there are remarkable similarities and/or analogies between the different ribosome biogenesis pathways 
that may exist and are worth being highlighted. First, the presence of ribosome biogenesis factor sequence homologs between archaea and eukaryotes suggests a common origin of the archaeal-eukaryotic ribosome biogenesis pathway (Ebersberger et al., 2014). Intriguingly, these sequence homologs are known to predominantly act during the latest steps of eukaryotic SSU and LSU maturation. Second, the presence of structural and/or functional mimicry conserved across the tree of life suggests that, despite an apparent sequence/structure divergence between most ribosome biogenesis factors, some steps have similar molecular constraints across the tree of life that are overcome by functionally equivalent molecular inventions [discussed in Ferreira-Cerca (2017); Jüttner et al. (2020)]. This seems to be particularly true in the context of the late steps of the small ribosomal subunit biogenesis (Ferreira-Cerca, 2017; Knüppel et al., 2018). Notably, despite the absence of apparent sequence and structural conservation between bacterial and eukaryotic ribosome biogenesis factors, those, for example, involved in the late steps of SSU maturation remarkably cluster within an analogous structural region on the nascent $\mathrm{SSU}$, i.e., regions that form the future functional centers. This suggests that binding of these ribosome biogenesis factors may ensure functional testing and avoid premature release of the nascent ribosomal subunits into the translational pool (Strunk et al., 2011, 2012; Ferreira-Cerca, 2017; Ghalei et al., 2017; Parker et al., 2019).

Furthermore, the ribosome biogenesis factors sequence homologs are not evenly distributed across all archaeal genomes, but follow the reductive evolution trend observed for the r-proteins, thereby suggesting a simplification of the ribosome biogenesis pathway in these organisms, e.g., euryarchaeota or nanoarchaeota, whereas ribosome synthesis in the TACK superphylum may generally be more complex due to the presence of additional $r$ - proteins or ribosome biogenesis factors (Lecompte et al., 2002; Yutin et al., 2012; Ebersberger et al., 2014; Zaremba-Niedzwiedzka et al., 2017; Figures 1, 3). However, in organisms showing an apparent reduced ribosome biogenesis complexity, the addition or molecular exchange by unknown archaeal specific r-proteins and/or ribosome biogenesis factors cannot be fully excluded.

So far, the functional analysis of archaeal ribosome biogenesis factors is rather limited, and only a few have been established in vivo. Most of these characterized factors are sequence homologs of genuine eukaryotic ribosome biogenesis factors [see Ebersberger et al. (2014) for a complete list of candidates]. Among them, the dimethyltransferase KsgA/Dim1 [see above and Grünberger et al. (2020); Knüppel et al. (2021)], or the Rio ATPase/Kinase family members are implicated in the late steps of SSU maturation, where they probably play a role similar to their eukaryotic counterparts (Knüppel et al., 2018). Similarly, the endonuclease Nob1 is implicated in the maturation of the $16 \mathrm{~S}$ rRNA 3'end in vitro (Veith et al., 2012; Qi et al., 2020; Figure 2). Collectively, these analyses suggest that the late steps of archaeal SSU biogenesis is a simplified version of the late steps of eukaryotes SSU maturation (Ferreira-Cerca, 2017; Knüppel et al., 2018). However, the degree of functional conservation and interactions of ribosome biogenesis factors such as the archaeal homologs of Rio1, Fap7, Dim1, Pno1, or Nob1, which form an important functional network involved in the late steps of eukaryotic SSU maturation, remains to be explored. Gaining information on these points will surely offer important insights on the molecular evolution and adaptation of the ribosome biogenesis pathway.

Last, the endonuclease endA known to be involved in the maturation of intron-containing tRNAs (Clouet-d'Orval et al., 2018) has been recently implicated in rRNA processing, thereby indicating a functional coordination of tRNA and rRNA maturation in archaea (Qi et al., 2020; Schwarz et al., 2020; Figure 2).

\section{PERSPECTIVES AND OUTLOOK}

Among the numerous challenges and outstanding questions ahead, the comprehensive identification and functional characterization of factors implicated in archaeal ribosome biogenesis are a key step to further understanding the common and specific features of archaeal ribosome biogenesis. In addition, recent improvement of cryo-electron microscopy analysis has been instrumental to better characterize bacterial and eukaryotic ribosome biogenesis pathways (Davis and Williamson, 2017; Baßler and Hurt, 2019; Klinge and Woolford, 2019). A similar revolution is still to come in the archaeal ribosome biogenesis field and will be important to decipher functional and structural analogies conserved across the tree of life and further improve our view on the evolutionary history of the ribosome biogenesis pathway and how molecular and environmental constraints may have (re-)shaped the ribosome biogenesis molecular dance.

Furthermore, and as discussed, the ribosome biogenesis sequence homologs and r-proteins are not ubiquitously distributed across archaea. Therefore, it is of interest to define the extent of archaeal ribosome biogenesis diversity and functional adaptation (Seistrup et al., 2017; Birkedal et al., 2020; SasChen et al., 2020; Knüppel et al., 2021). Additionally, future metagenomics analyses will certainly increase the numbers of newly identified archaea. Accordingly, learning from archaeal biodiversity, changes and adaptation of the ribosome biogenesis pathway are expected to be discovered; however, the formal analysis of this biodiversity is only possible with the advance of culturomics (Bilen et al., 2018; Lewis et al., 2021) and the fast implementation of genetic manipulation in multiple archaeal organisms.

\section{AUTHOR CONTRIBUTIONS}

PL and SF-C wrote the manuscript. Both authors contributed to the article and approved the submitted version.

\section{FUNDING}

Work in the SF-C laboratory is supported by intramural funding from the department of Biochemistry III "House of the Ribosome," by the German Research Foundation 
(DFG): individual research grant (FE1622/2-1), and collaborative research center SFB/CRC 960 (SFB960-AP1 and SFB960B13) "RNP biogenesis: assembly of ribosomes and nonribosomal RNPs and control of their function." Open access publishing of this work was partly supported by the German Research Foundation (DFG) within the funding program Open Access Publishing.

\section{REFERENCES}

Agalarov, S., Yusupov, M., and Yusupova, G. (2016). "Reconstitution of Functionally Active Thermus thermophilus 30S Ribosomal Subunit from Ribosomal 16S RNA and Ribosomal Proteins," in Nucleic Acid Crystallography: Methods and Protocols, ed. E. Ennifar (New York, NY: Springer New York), 303-314. doi: 10.1007/978-1-4939-2763-0_19

Albers, S.-V., Forterre, P., Prangishvili, D., and Schleper, C. (2013). The legacy of Carl Woese and Wolfram Zillig: from phylogeny to landmark discoveries. Nat. Rev. Micro. 11, 713-719. doi: 10.1038/nrmicro3124

Altamura, S., Caprini, E., Sanchez, M., and Londei, P. (1991). Early assembly proteins of the large ribosomal subunit of the thermophilic archaebacterium Sulfolobus. Identification and binding to heterologous rRNA species. J. Biol. Chem. 266, 6195-6200. doi: 10.1016/s0021-9258(18)38103-1

Armache, J.-P., Anger, A. M., Márquez, V., Franckenberg, S., Fröhlich, T., Villa, E., et al. (2013). Promiscuous behaviour of archaeal ribosomal proteins: implications for eukaryotic ribosome evolution. Nucleic Acids Res. 41, 12841293. doi: 10.1093/nar/gks1259

Bahram, M., Anslan, S., Hildebrand, F., Bork, P., and Tedersoo, L. (2019). Newly designed 16S rRNA metabarcoding primers amplify diverse and novel archaeal taxa from the environment. Environ. Microbiol. Rep. 11, 487-494. doi: 10.1111/ 1758-2229.12684

Ban, N., Beckmann, R., Cate, J. H. D., Dinman, J. D., Dragon, F., Ellis, S. R., et al. (2014). A new system for naming ribosomal proteins. Curr. Opin. Struct. Biol. 24, 165-169.

Baßler, J., and Hurt, E. (2019). Eukaryotic Ribosome Assembly. Annu. Rev. Biochem. 88, 281-306. doi: 10.1146/annurev-biochem-013118-110817

Bilen, M., Dufour, J.-C., Lagier, J.-C., Cadoret, F., Daoud, Z., Dubourg, G., et al. (2018). The contribution of culturomics to the repertoire of isolated human bacterial and archaeal species. Microbiome 6:94.

Birkedal, U., Beckert, B., Wilson, D. N., and Nielsen, H. (2020). The 23S Ribosomal RNA From Pyrococcus furiosus Is Circularly Permuted. Front. Microbiol. 11:582022. doi: 10.3389/fmicb.2020.582022

Boccaletto, P., Machnicka, M. A., Purta, E., Piątkowski, P., Bagiński, B., Wirecki, T. K., et al. (2018). MODOMICS: a database of RNA modification pathways. 2017 update. Nucleic Acids Res. 46, D303-D307.

Bowman, J. C., Petrov, A. S., Frenkel-Pinter, M., Penev, P. I., and Williams, L. D. (2020). Root of the Tree: the Significance, Evolution, and Origins of the Ribosome. Chem. Rev. 120, 4848-4878. doi: 10.1021/acs.chemrev.9b00742

Breuer, R., Gomes-Filho, J.-V., and Randau, L. (2021). Conservation of Archaeal C/D Box sRNA-Guided RNA Modifications. Front. Microbiol. 12:654029. doi: 10.3389/fmicb.2021.654029

Brewer, T. E., Albertsen, M., Edwards, A., Kirkegaard, R. H., Rocha, E. P. C., and Fierer, N. (2020). Unlinked rRNA genes are widespread among bacteria and archaea. ISME J. 14, 597-608. doi: 10.1038/s41396-019-0552-3

Bunner, A. E., Nord, S., Wikström, P. M., and Williamson, J. R. (2010). The Effect of Ribosome Assembly Cofactors on In Vitro 30S Subunit Reconstitution. J. Mol. Biol. 398, 1-7. doi: 10.1016/j.jmb.2010.02.036

Cheng, J., Baßler, J., Fischer, P., Lau, B., Kellner, N., Kunze, R., et al. (2019). Thermophile 90S Pre-ribosome Structures Reveal the Reverse Order of Co-transcriptional 18S rRNA Subdomain Integration. Mol Cell 75, 1256 1269.e7.

Cheng, J., Kellner, N., Berninghausen, O., Hurt, E., and Beckmann, R. (2017). 3.2$\AA$-resolution structure of the $90 \mathrm{~S}$ preribosome before A1 pre-rRNA cleavage. Nat. Struct. Mol. Biol. 24, 954-964. doi: 10.1038/nsmb.3476

Ciammaruconi, A., and Londei, P. (2001). In Vitro Processing of the 16S rRNA of the Thermophilic Archaeon Sulfolobus solfataricus. J. Bacteriol. 183, 38663874. doi: 10.1128/jb.183.13.3866-3874.2001

\section{ACKNOWLEDGMENTS}

The authors would like to apologize to our colleagues whose work could not be highlighted and/or discussed in this review. SF-C like to acknowledge Michael Jüttner and Robert Knüppel (University of Regensburg) for fruitful and inspiring discussions on archaeal ribosome biogenesis evolution.

Clouet-d'Orval, B., Batista, M., Bouvier, M., Quentin, Y., Fichant, G., Marchfelder, A., et al. (2018). Insights into RNA-processing pathways and associated RNAdegrading enzymes in Archaea. FEMS Microbiol. Rev. 42, 579-613. doi: 10. 1093/femsre/fuy016

Cockram, C., Thierry, A., Gorlas, A., Lestini, R., and Koszul, R. (2021). Euryarchaeal genomes are folded into SMC-dependent loops and domains, but lack transcription-mediated compartmentalization. Mol. Cell 81, 459-472.e10.

Connolly, K., Rife, J. P., and Culver, G. (2008). Mechanistic insight into the ribosome biogenesis functions of the ancient protein KsgA. Mol. Microbiol. 70, 1062-1075. doi: 10.1111/j.1365-2958.2008.06485.x

Coureux, P.-D., Lazennec-Schurdevin, C., Bourcier, S., Mechulam, Y., and Schmitt, E. (2020). Cryo-EM study of an archaeal 30S initiation complex gives insights into evolution of translation initiation. Commun. Biol. 3:58.

Culver, G. M. (2003). Assembly of the 30 S ribosomal subunit. Biopolymers 68, 234-249.

Czekay, D. P., and Kothe, U. (2021). H/ACA Small Ribonucleoproteins: structural and Functional Comparison Between Archaea and Eukaryotes. Front. Microbiol. 12:654370. doi: 10.3389/fmicb.2021.654370

Dao Duc, K., Batra, S. S., Bhattacharya, N., Cate, J. H. D., and Song, Y. S. (2019). Differences in the path to exit the ribosome across the three domains of life. Nucleic Acids Res. 47, 4198-4210. doi: 10.1093/nar/gkz106

Davis, J. H., and Williamson, J. R. (2017). Structure and dynamics of bacterial ribosome biogenesis. Philos. Trans. R. Soc. Lond. B Biol. Sci. 372:20160181. doi: 10.1098/rstb.2016.0181

de la Cruz, J., Karbstein, K., and Woolford, J. L. (2015). Functions of Ribosomal Proteins in Assembly of Eukaryotic Ribosomes In Vivo. Annu. Rev. Biochem. 84, 93-129. doi: 10.1146/annurev-biochem-060614-033917

Dennis, P. P., Tripp, V., Lui, L., Lowe, T., and Randau, L. (2015). C/D box sRNAguided 2'-O-methylation patterns of archaeal rRNA molecules. BMC Genomics 16:632. doi: 10.1186/s12864-015-1839-z

Díaz-López, I., Toribio, R., Berlanga, J. J., and Ventoso, I. (2019). An mRNAbinding channel in the ES6S region of the translation 48S-PIC promotes RNA unwinding and scanning. Elife 8:e48246.

Durovic, P., and Dennis, P. P. (1994). Separate pathways for excision and processing of $16 \mathrm{~S}$ and $23 \mathrm{~S}$ rRNA from the primary rRNA operon transcript from the hyperthermophilic archaebacterium Sulfolobus acldocaldarius: similarities to eukaryotic rRNA processing. Mol. Microbiol. 13, 229-242. doi: 10.1111/j.1365-2958.1994.tb00418.x

Ebersberger, I., Simm, S., Leisegang, M. S., Schmitzberger, P., Mirus, O., von Haeseler, A., et al. (2014). The evolution of the ribosome biogenesis pathway from a yeast perspective. Nucleic Acids Res. 42, 1509-1523. doi: 10.1093/nar/ gkt1137

Ferreira-Cerca, S. (2017). "Life and Death of Ribosomes in Archaea," in RNA Metabolism and Gene Expression in Archaea, ed. B. Clouet-d'Orval (Cham: Springer International Publishing), 129-158. doi: 10.1007/978-3-319-65 795-0_6

Ferreira-Cerca, S., Pöll, G., Kühn, H., Neueder, A., Jakob, S., Tschochner, H., et al. (2007). Analysis of the In Vivo Assembly Pathway of Eukaryotic 40S Ribosomal Proteins. Mol. Cell 28, 446-457. doi: 10.1016/j.molcel.2007.09.029

Formenoy, L. J., Cunningham, P. R., Nurse, K., Pleij, C. W. A., and Ofengand, J. (1994). Methylation of the conserved A1518-A1519 in Escherichia coli 16S ribosomal RNA by the ksgA methyltransferase is influenced by methylations around the similarly conserved U1512-G1523 base pair in the $3^{\prime}$ terminal hairpin. Biochimie 76, 1123-1128. doi: 10.1016/0300-9084(94)90040-x

Fox, G. E., Magrum, L. J., Balch, W. E., Wolfe, R. S., and Woese, C. R. (1977). Classification of methanogenic bacteria by $16 \mathrm{~S}$ ribosomal RNA characterization. Proc. Natl. Acad. Sci. U. S. A. 74, 4537-4541. doi: 10.1073/ pnas.74.10.4537 
Fujii, K., Susanto, T. T., Saurabh, S., and Barna, M. (2018). Decoding the Function of Expansion Segments in Ribosomes. Mol. Cell 72, 1013-1020.e6.

Gerbi, S. (1996). "Expansion segments: regions of variable size that interrupt the universal core secondary structure of ribosomal RNA," in Ribosomal RNA Structure, Evolution, Processing, and Function in Protein Biosynthesis, eds R. A. Zimmermann and A. E. Dahlberg (Boca Raton, FL: Telford-CRC Press), 71-87.

Gerbi, S. A. (1986). The evolution of eukaryotic ribosomal DNA. Biosystems 19, 247-258. doi: 10.1016/0303-2647(86)90001-8

Ghalei, H., Trepreau, J., Collins, J. C., Bhaskaran, H., Strunk, B. S., and Karbstein, K. (2017). The ATPase Fap7 Tests the Ability to Carry Out Translocation-like Conformational Changes and Releases Dim1 during 40S Ribosome Maturation. Mol. Cell 67, 990-1000.e3.

Green, R., and Noller, H. F. (1999). Reconstitution of Functional 50S Ribosomes from in Vitro Transcripts of Bacillus stearothermophilus 23S rRNA. Biochemistry 38, 1772-1779. doi: 10.1021/bi982246a

Grosjean, H., Breton, M., Sirand-Pugnet, P., Tardy, F., Thiaucourt, F., Citti, C., et al. (2014). Predicting the Minimal Translation Apparatus: lessons from the Reductive Evolution of Mollicutes. PLoS Genet. 10:e1004363. doi: 10.1371/ journal.pgen.1004363

Grosjean, H., Gaspin, C., Marck, C., Decatur, W. A., and de Crécy-Lagard, V. (2008). RNomics and Modomics in the halophilic archaea Haloferax volcanii: identification of RNA modification genes. BMC Genomics 9:470. doi: 10.1186/ 1471-2164-9-470

Grünberger, F., Knüppel, R., Jüttner, M., Fenk, M., Borst, A., Reichelt, R., et al. (2020). Exploring prokaryotic transcription, operon structures, rRNA maturation and modifications using Nanopore-based native RNA sequencing. BioRxiv [Preprint]. doi: 10.1101/2019.12.18.880849

Hadjiolov, A. A. (1985). The Nucleolus and Ribosome Biogenesis. Vienna: SpringerVerlag Wien.

Hage, A. E., and Tollervey, D. (2004). A Surfeit of Factors: why is Ribosome Assembly So Much More Complicated in Eukaryotes than Bacteria? RNA Biol. 1, 9-14. doi: 10.4161/rna.1.1.932

Henras, A. K., Plisson-Chastang, C., O'Donohue, M.-F., Chakraborty, A., and Gleizes, P.-E. (2015). An overview of pre-ribosomal RNA processing in eukaryotes. Wiley Interdiscip. Rev. RNA 6, 225-242. doi: 10.1002/wrna.1269

Higo, K., Held, W., Kahan, L., and Nomura, M. (1973). Functional correspondence between $30 \mathrm{~S}$ ribosomal proteins of Escherichia coli and Bacillus stearothermophilus. Proc. Natl. Acad. Sci. U. S. A. 70, 944-948. doi: $10.1073 /$ pnas.70.3.944

Jüttner, M., Weiß, M., Ostheimer, N., Reglin, C., Kern, M., Knüppel, R., et al. (2020). A versatile cis-acting element reporter system to study the function, maturation and stability of ribosomal RNA mutants in archaea. Nucleic Acids Res. 48, 2073-2090. doi: 10.1093/nar/gkz1156

Kadumuri, R. V., and Janga, S. C. (2018). Epitranscriptomic Code and Its Alterations in Human Disease. Trends Mol. Med. 24, 886-903. doi: 10.1016/ j.molmed.2018.07.010

Klappenbach, J. A., Saxman, P. R., Cole, J. R., and Schmidt, T. M. (2001). rrndb: the Ribosomal RNA Operon Copy Number Database. Nucleic Acids Res. 29, 181-184. doi: 10.1093/nar/29.1.181

Klinge, S., and Woolford, J. L. (2019). Ribosome assembly coming into focus. Nat. Rev. Mol. Cell Biol. 20, 116-131. doi: 10.1038/s41580-018-0078-y

Knüppel, R., Christensen, R. H., Gray, F. C., Esser, D., Strauß, D., Medenbach, J., et al. (2018). Insights into the evolutionary conserved regulation of Rio ATPase activity. Nucleic Acids Res. 46, 1441-1456. doi: 10.1093/nar/gkx1236

Knüppel, R., Trahan, C., Kern, M., Wagner, A., Grünberger, F., Hausner, W., et al. (2021). Insights into synthesis and function of KsgA/Dim1-dependent rRNA modifications in archaea. Nucleic Acids Res. 49, 1662-1687. doi: 10.1093/nar/ gkaa1268

Krogh, N., Jansson, M. D., Häfner, S. J., Tehler, D., Birkedal, U., ChristensenDalsgaard, M., et al. (2016). Profiling of $2^{\prime}$-O-Me in human rRNA reveals a subset of fractionally modified positions and provides evidence for ribosome heterogeneity. Nucleic Acids Res. 44, 7884-7895. doi: 10.1093/nar/gkw482

Lafontaine, D., Delcour, J., Glasser, A.-L., Desgres, J., and Vandenhaute, J. (1994). The DIM1 Gene Responsible for the Conserved m62Am62A Dimethylation in the $3^{\prime}$-Terminal Loop of $18 \mathrm{~S}$ rRNA is Essential in Yeast. J. Mol. Biol. 241, 492-497. doi: 10.1006/jmbi.1994.1525

Lafontaine, D. L. J., and Tollervey, D. (1998). Birth of the snoRNPs: the evolution of the modification-guide snoRNAs. Trends Biochem. Sci. 23, 383-388. doi: 10.1016/s0968-0004(98)01260-2
Lecompte, O., Ripp, R., Thierry, J., Moras, D., and Poch, O. (2002). Comparative analysis of ribosomal proteins in complete genomes: an example of reductive evolution at the domain scale. Nucleic Acids Res. 30, 5382-5390. doi: 10.1093/ nar/gkf693

Lewis, W. H., Tahon, G., Geesink, P., Sousa, D. Z., and Ettema, T. J. G. (2021). Innovations to culturing the uncultured microbial majority. Nat. Rev. Microbiol. 19, 225-240. doi: 10.1038/s41579-020-00458-8

Li, S., and Mason, C. E. (2014). The Pivotal Regulatory Landscape of RNA Modifications. Annu. Rev. Genom. Hum. Genet. 15, 127-150. doi: 10.1146/ annurev-genom-090413-025405

Littlefield, J. W., and Dunn, D. B. (1958). Natural Occurrence of Thymine and Three Methylated Adenine Bases in Several Ribonucleic Acids. Nature 181, 254-255. doi: 10.1038/181254a0

Liu, K., Santos, D. A., Hussmann, J. A., Wang, Y., Sutter, B. M., Weissman, J. S., et al. (2021). Regulation of translation by methylation multiplicity of $18 \mathrm{~S}$ rRNA. Cell Rep. 34:108825. doi: 10.1016/j.celrep.2021.108825

Liu, Y., Makarova, K. S., Huang, W.-C., Wolf, Y. I., Nikolskaya, A. N., Zhang, X., et al. (2021). Expanded diversity of Asgard archaea and their relationships with eukaryotes. Nature 593, 553-557. doi: 10.1038/s41586-021-03494-3

Londei, P., Teichner, A., Cammarano, P., De Rosa, M., and Gambacorta, A. (1983). Particle weights and protein composition of the ribosomal subunits of the extremely thermoacidophilic archaebacterium Caldariella acidophila. Biochem. J. 209, 461-470. doi: 10.1042/bj2090461

Londei, P., Teixidò, J., Acca, M., Cammarano, P., and Amils, R. (1986). Total reconstitution of active large ribosomal subunits of the thermoacidophilic archaebacterium Sulfolobus solfataricus. Nucleic Acids Res. 14, 2269-2285.

Mangiarotti, G., and Chiaberge, S. (1997). Reconstitution of Functional Eukaryotic Ribosomes fromDictyostelium discoideum Ribosomal Proteins and RNA. J. Biol. Chem. 272, 19682-19687. doi: 10.1074/jbc.272.32.19682

Márquez, V., Fröhlich, T., Armache, J.-P., Sohmen, D., Dönhöfer, A., Mikolajka, A., et al. (2011). Proteomic Characterization of Archaeal Ribosomes Reveals the Presence of Novel Archaeal-Specific Ribosomal Proteins. J. Mol. Biol. 405, 1215-1232. doi: 10.1016/j.jmb.2010.11.055

Melnikov, S., Ben-Shem, A., Garreau de Loubresse, N., Jenner, L., Yusupova, G., and Yusupov, M. (2012). One core, two shells: bacterial and eukaryotic ribosomes. Nat. Struct. Mol. Biol. 19, 560-567. doi: 10.1038/nsmb.2313

Melnikov, S., Manakongtreecheep, K., and Söll, D. (2018). Revising the Structural Diversity of Ribosomal Proteins Across the Three Domains of Life. Mol. Biol. Evol. 35, 1588-1598. doi: 10.1093/molbev/msy021

Mendler, K., Chen, H., Parks, D. H., Lobb, B., Hug, L. A., and Doxey, A. C. (2019). AnnoTree: visualization and exploration of a functionally annotated microbial tree of life. Nucleic Acids Res. 47, 4442-4448. doi: 10.1093/nar/gkz246

Mullineux, S.-T., and Lafontaine, D. L. J. (2012). Mapping the cleavage sites on mammalian pre-rRNAs: where do we stand? Biochimie 94, 1521-1532. doi: 10.1016/j.biochi.2012.02.001

Nakao, A., Yoshihama, M., and Kenmochi, N. (2004). RPG: the Ribosomal Protein Gene database. Nucleic Acids Res. 32, D168-D170.

Nierhaus, K. H. (1991). The assembly of prokaryotic ribosomes. Biochimie 73, 739-755. doi: 10.1016/0300-9084(91)90054-5

Nierhaus, K. H., and Dohme, F. (1974). Total reconstitution of functionally active 50 S ribosomal subunits from Escherichia coli. Proc. Natl. Acad. Sci. U. S. A. 71, 4713-4717. doi: 10.1073/pnas.71.12.4713

Nierhaus, K. H., and Lafontaine, D. L. (2004). "Ribosome Assembly," in Protein Synthesis and Ribosome Structure, esd K. H. Nierhaus and D. N. Wilson (KGaA: Wiley-VCH Verlag GmbH \& Co), 85-143. doi: 10.1002/3527603433.ch3

Nikolay, R., Hilal, T., Qin, B., Mielke, T., Bürger, J., Loerke, J., et al. (2018). Structural Visualization of the Formation and Activation of the 50S Ribosomal Subunit during In Vitro Reconstitution. Mol. Cell 70, 881-893.e3.

Nomura, M. (1999). Regulation of Ribosome Biosynthesis in Escherichia coli and Saccharomyces cerevisiae: diversity and Common Principles. J. Bacteriol. 181, 6857-6864. doi: 10.1128/jb.181.22.6857-6864.1999

Nürenberg-Goloub, E., Kratzat, H., Heinemann, H., Heuer, A., Kötter, P., Berninghausen, O., et al. (2020). Molecular analysis of the ribosome recycling factor ABCE1 bound to the 30S post-splitting complex. EMBO J. 39:e103788.

Omer, A. D., Ziesche, S., Decatur, W. A., Fournier, M. J., and Dennis, P. P. (2003). RNA-modifying machines in archaea. Mol. Microbiol. 48, 617-629. doi: 10. 1046/j.1365-2958.2003.03483.x

Parker, M. D., Collins, J. C., Korona, B., Ghalei, H., and Karbstein, K. (2019). A kinase-dependent checkpoint prevents escape of immature ribosomes into 
the translating pool. PLoS Biol. 17:e3000329. doi: 10.1371/journal.pbio.300 0329

Parker, M. S., Sallee, F. R., Park, E. A., and Parker, S. L. (2015). Homoiterons and expansion in ribosomal RNAs. FEBS Open Bio. 5, 864-876. doi: 10.1016/j.fob. 2015.10.005

Penev, P. I., Fakhretaha-Aval, S., Patel, V. J., Cannone, J. J., Gutell, R. R., Petrov, A. S., et al. (2020). Supersized Ribosomal RNA Expansion Segments in Asgard Archaea. Genome Biol. Evol. 12, 1694-1710. doi: 10.1093/gbe/evaa170

Petrov, A. S., Gulen, B., Norris, A. M., Kovacs, N. A., Bernier, C. R., Lanier, K. A., et al. (2015). History of the ribosome and the origin of translation. Proc. Natl. Acad. Sci.U. S. A. 112, 15396-15401.

Piekna-Przybylska, D., Decatur, W. A., and Fournier, M. J. (2008). The 3D rRNA modification maps database: with interactive tools for ribosome analysis. Nucleic Acids Res. 36, D178-D183.

Qi, L., Li, J., Jia, J., Yue, L., and Dong, X. (2020). Comprehensive analysis of the pre-ribosomal RNA maturation pathway in a methanoarchaeon exposes the conserved circularization and linearization mode in archaea. RNA Biol. 17, 1427-1441. doi: 10.1080/15476286.2020.1771946

Ramesh, M., and Woolford, J. L. Jr. (2016). Eukaryote-specific rRNA expansion segments function in ribosome biogenesis. RNA 22, 1153-1162. doi: 10.1261/ rna.056705.116

Roth, H. E., and Nierhaus, K. H. (1980). Assembly Map of the 50-S Subunit from Escherichia coli Ribosomes, Covering the Proteins Present in the First Reconstitution Intermediate Particle. Eur. J. Biochem. 103, 95-98. doi: 10.1111/ j.1432-1033.1980.tb04292.x

Ruggero, D., Ciammaruconi, A., and Londei, P. (1998). The chaperonin of the archaeon Sulfolobus solfataricus is an RNA-binding protein that participates in ribosomal RNA processing. EMBO J. 17, 3471-3477. doi: 10.1093/emboj/17. 12.3471

Sanchez, E. M., Londei, P., and Amils, R. (1996). Total reconstitution of active small ribosomal subunits of the extreme halophilic archaeon Haloferax mediterranei. Biochim. Biophys. Acta 1292, 140-144. doi: 10.1016/0167-4838(95)00179-4

Sanchez, M. E., Urena, D., Amils, R., and Londei, P. (1990). In vitro reassembly of active large ribosomal subunits of the halophilic archaebacterium Haloferax mediterranei. Biochemistry 29, 9256-9261. doi: 10.1021/bi00491a021

Sas-Chen, A., Thomas, J. M., Matzov, D., Taoka, M., Nance, K. D., Nir, R., et al. (2020). Dynamic RNA acetylation revealed by quantitative cross-evolutionary mapping. Nature 583, 638-643. doi: 10.1038/s41586-020-2418-2

Schmid, G., and Böck, A. (1982). The ribosomal protein composition of five methanogenic bacteria. Zentralblatt Für Bakteriologie Mikrobiologie Und Hygiene: I. Abt. Originale C: Allgemeine, Angewandte Und Ökologische Mikrobiologie 3, 347-353. doi: 10.1016/s0721-9571(82)80013-6

Schwarz, T. S., Berkemer, S. J., Bernhart, S. H., Weiß, M., Ferreira-Cerca, S., Stadler, P. F., et al. (2020). Splicing Endonuclease Is an Important Player in rRNA and tRNA Maturation in Archaea. Front. Microbiol. 11:594838. doi: 10.3389/fmicb. 2020.594838

Seistrup, K. H., Rose, S., Birkedal, U., Nielsen, H., Huber, H., and Douthwaite, S. (2017). Bypassing rRNA methylation by RsmA/Dimlduring ribosome maturation in the hyperthermophilic archaeon Nanoarchaeum equitans. Nucleic Acids Res. 45, 2007-2015.

Shajani, Z., Sykes, M. T., and Williamson, J. R. (2011). Assembly of Bacterial Ribosomes. Annu. Rev. Biochem. 80, 501-526. doi: 10.1146/annurev-biochem062608-160432

Shankar, V., Rauscher, R., Reuther, J., Gharib, W. H., Koch, M., and Polacek, N. (2020). rRNA expansion segment $27 \mathrm{Lb}$ modulates the factor recruitment capacity of the yeast ribosome and shapes the proteome. Nucleic Acids Res. 48, 3244-3256. doi: 10.1093/nar/gkaa003

Sharma, S., and Lafontaine, D. L. J. (2015). 'View From A Bridge': a New Perspective on Eukaryotic rRNA Base Modification. Trends Biochem. Sci. 40, 560-575. doi: $10.1016 /$ j.tibs.2015.07.008

Sleiman, S., and Dragon, F. (2019). Recent Advances on the Structure and Function of RNA Acetyltransferase Kre33/NAT10. Cells 8:1035. doi: 10.3390/ cells 8091035

Sloan, K. E., Warda, A. S., Sharma, S., Entian, K.-D., Lafontaine, D. L. J., and Bohnsack, M. T. (2016). Tuning the ribosome: the influence of rRNA modification on eukaryotic ribosome biogenesis and function. RNA Biol. 14, 1138-1152. doi: 10.1080/15476286.2016.1259781
Sobolev, A., Solovyev, M., Ivanova, V., Kochetkova, T., Merkel, A., Razin, S., et al. (2021). 3C-seq-captured chromosome conformation of the hyperthermophilic archaeon Thermofilum adornatum. BioRxiv [Preprint]. doi: 10.1101/2021.04. 30.439615

Spang, A., Saw, J. H., Jorgensen, S. L., Zaremba-Niedzwiedzka, K., Martijn, J., Lind, A. E., et al. (2015). Complex archaea that bridge the gap between prokaryotes and eukaryotes. Nature 521, 173-179. doi: 10.1038/nature14447

Stepanov, V. G., and Fox, G. E. (2021). Expansion segments in bacterial and archaeal 5S ribosomal RNAs. RNA 27, 133-150. doi: 10.1261/rna.077123.120

Stoddard, S. F., Smith, B. J., Hein, R., Roller, B. R. K., and Schmidt, T. M. (2015). rrnDB: improved tools for interpreting rRNA gene abundance in bacteria and archaea and a new foundation for future development. Nucleic Acids Res. 43, D593-D598.

Strunk, B. S., Loucks, C. R., Su, M., Vashisth, H., Cheng, S., Schilling, J., et al. (2011). Ribosome Assembly Factors Prevent Premature Translation Initiation by $40 \mathrm{~S}$ Assembly Intermediates. Science 333, 1449-1453. doi: 10.1126/science. 1208245

Strunk, B. S., Novak, M. N., Young, C. L., and Karbstein, K. (2012). A translationlike cycle is a quality control checkpoint for maturing $40 \mathrm{~S}$ ribosome subunits. Cell 150, 111-121. doi: 10.1016/j.cell.2012.04.044

Takemata, N., and Bell, S. D. (2021). Multi-scale architecture of archaeal chromosomes. Mol. Cell 81, 473-487.e6.

Tang, T. H., Rozhdestvensky, T. S., d'Orval, B. C., Bortolin, M.-L., Huber, H., Charpentier, B., et al. (2002). RNomics in Archaea reveals a further link between splicing of archaeal introns and rRNA processing. Nucleic Acids Res. 30, 921-930. doi: 10.1093/nar/30.4.921

Taoka, M., Nobe, Y., Yamaki, Y., Sato, K., Ishikawa, H., Izumikawa, K., et al. (2018). Landscape of the complete RNA chemical modifications in the human $80 \mathrm{~S}$ ribosome. Nucleic Acids Res. 46, 9289-9298. doi: 10.1093/nar/gky811

Teixidò, J., Altamura, S., Londei, P., and Amils, R. (1989). Structural and functional exchangeability of $5 \mathrm{~S}$ RNA species from the eubacterium E.coli and the thermoacidophilic archaebacterium Sulfolobus solfataricus. Nucleic Acids Res. 17, 845-851. doi: 10.1093/nar/17.3.845

Thomson, E., Ferreira-Cerca, S., and Hurt, E. (2013). Eukaryotic ribosome biogenesis at a glance. J. Cell Sci. 126, 4815-4821. doi: 10.1242/jcs.111948

Tirumalai, M. R., Kaelber, J. T., Park, D. R., Tran, Q., and Fox, G. E. (2020). Cryoelectron microscopy visualization of a large insertion in the $5 \mathrm{~S}$ ribosomal RNA of the extremely halophilic archaeon Halococcus morrhuae. FEBS Open Bio. 10, 1938-1946. doi: 10.1002/2211-5463.12962

Traub, P., and Nomura, M. (1968). Structure and function of E. coli ribosomes. V. Reconstitution of functionally active $30 \mathrm{~S}$ ribosomal particles from RNA and proteins. Proc. Natl. Acad. Sci. U. S. A. 59, 777-784. doi: 10.1073/pnas.59.3.777

Van Buul, C. P. J. J., Hamersma, M., Visser, W., and Van Knippenberg, P. H. (1984). Partial methylation of two adjacent adenosines in ribosomes from Euglena gracilis chloroplasts suggests evolutionary loss of an intermediate stage in the methyl-transfer reaction. Nucleic Acids Res. 12, 9205-9208. doi: 10.1093/nar/ 12.23.9205

Veith, T., Martin, R., Wurm, J. P., Weis, B. L., Duchardt-Ferner, E., Safferthal, C., et al. (2012). Structural and functional analysis of the archaeal endonuclease Nob1. Nucleic Acids Res. 40, 3259-3274. doi: 10.1093/nar/gkr1186

Vogel, D. W., Hartmann, R. K., Bartsch, M., Subramanian, A. R., Kleinow, W., O'Brien, T. W., et al. (1984). Reconstitution of $50 \mathrm{~S}$ ribosomal subunits from Bacillus stearothermophilus with $5 \mathrm{~S}$ RNA from spinach chloroplasts and low$\mathrm{M} r$ RNA from mitochondria of Locusta migratoria and bovine liver. FEBS Lett. 169, 67-72. doi: 10.1016/0014-5793(84)80291-4

Warner, J. R. (1999). The economics of ribosome biosynthesis in yeast. Trends Biochem. Sci. 24, 437-440. doi: 10.1016/s0968-0004(99)01460-7

Woese, C. R., and Fox, G. E. (1977). Phylogenetic structure of the prokaryotic domain: the primary kingdoms. Proc. Natl. Acad. Sci.U. S. A. 74, 5088-5090. doi: $10.1073 /$ pnas.74.11.5088

Woese, C. R., Kandler, O., and Wheelis, M. L. (1990). Towards a natural system of organisms: proposal for the domains Archaea, Bacteria, and Eucarya. Proc. Natl. Acad. Sci. U. S. A. 87, 4576-4579. doi: 10.1073/pnas.87.12.4576

Woolford, J. L., and Baserga, S. J. (2013). Ribosome Biogenesis in the Yeast Saccharomyces cerevisiae. Genetics 195, 643-681. doi: 10.1534/genetics.113. 153197

Yip, W. S. V., Vincent, N. G., and Baserga, S. J. (2013). Ribonucleoproteins in Archaeal Pre-rRNA Processing and Modification. Archaea 2013:614735. 
Yutin, N., Puigbò, P., Koonin, E. V., and Wolf, Y. I. (2012). Phylogenomics of Prokaryotic Ribosomal Proteins. PLoS One 7:e36972. doi: 10.1371/journal.pone. 0036972

Zaremba-Niedzwiedzka, K., Caceres, E. F., Saw, J. H., Bäckström, D., Juzokaite, L., Vancaester, E., et al. (2017). Asgard archaea illuminate the origin of eukaryotic cellular complexity. Nature 541, 353-358. doi: 10.1038/nature21031

Zorbas, C., Nicolas, E., Wacheul, L., Huvelle, E., Heurgué-Hamard, V., and Lafontaine, D. L. J. (2015). The human $18 \mathrm{~S}$ rRNA base methyltransferases DIMT1L and WBSCR22-TRMT112 but not rRNA modification are required for ribosome biogenesis. Mol. Biol. Cell 26, 2080-2095.
Conflict of Interest: The authors declare that the research was conducted in the absence of any commercial or financial relationships that could be construed as a potential conflict of interest.

Copyright (c) 2021 Londei and Ferreira-Cerca. This is an open-access article distributed under the terms of the Creative Commons Attribution License (CC BY). The use, distribution or reproduction in other forums is permitted, provided the original author(s) and the copyright owner(s) are credited and that the original publication in this journal is cited, in accordance with accepted academic practice. No use, distribution or reproduction is permitted which does not comply with these terms. 